\title{
Combo antibody efforts up, despite regulatory uncertainties
}

Antibody therapies have traditionally consisted of drugs that can deliver a strong blow to a single target, such as a cancer cell, with great specificity. But companies have made recent investments to improve these molecules by equipping them with multipronged attacksdeveloping so-called 'multispecific' antibodies that have two or more simultaneous targets.

"There's definitely a trend of multispecific therapies," says immunologist Gregory Adams of the Fox Chase Cancer Center in Philadelphia. And that trend has reached big pharma.

In October of last year, for example, MacroGenics, a biotechnology firm in Rockville, Maryland, announced that it had received $\$ 60$ million from the German drug company Boehringer Ingelheim as part of a collaboration to develop a platform for antibodies that can bind two different molecules at the same time. This follows from a $\$ 505$ million deal four years ago made by New York's Bristol-Myers Squibb to acquire Adnexus Therapeutics, a Waltham, Massachusetts-based biotech company developing multispecific biologics. And this summer, the Indiana-based pharmaceutical giant Eli Lilly announced a "multi-million dollar" investment to double its capacity in drugs that have multiple targets.

As part of the plan-released on 28 June at the BIO International Convention in Washington, DC-Lilly will double the total number of its employees dedicated to the discovery and protein engineering of such drugs from around 35 to about 80 . The drugmaker says it has at least seven multispecific biologics in development at present, including a protein-based medicine for diabetes that it anticipates will enter clinical trials by the end of this year.

Part of the push for developing multispecific therapeutics has to do with the difficulty of combining currently available forms of biologic drugs. "Some biologics are not compatible in the same bottle," says Lilly's vice president of biotechnology discovery research Tom Bumol. That means medicines must be given in multiple injections rather than one easy shot.

Dane Wittrup, a protein engineering expert at the Massachusetts Institute of Technology in Cambridge, Massachusetts, also notes that the multispecific strategy should help extend the therapeutic effect of medicines, particularly in oncology. "Simultaneously attacking two targets on a cancer cell may help forestall the emergence of drug resistance," he says.

\section{Irregular regulation}

Although enthusiasm for multispecific drugs has increased, the regulatory environment for these new creations is uncertain, especially when they are designed to affect more than one novel target. Traditionally, hitting two or more biological targets has required mixing multiple drugs, each of which has to undergo a separate clinical testing before being tested in combination, although this process may be eased in the future (Nat. Med. 17, 270, 2011). Additionally, there are concerns that multispecific antibodies might carry an increased risk of severe inflammatory reactions-a side effect seen in the disastrous 2006 UK trial of the single antibody TGN1412.

Precedent exists, however, for combining antibody targets. Two years ago, for example, Danish drugmaker Symphogen was able to initiate a test of a dual antibody mixture against cancer without being required by the US Food and Drug Administration (FDA) to evaluate the antibodies independently. The reason is that the two kinds of cells engineered to produce the antibodies are mixed together in manufacturing, rather than housed in different vats.

Regulators across the Atlantic have been bolder and have already given a bona fide multispecific antibody a go-ahead. Catumaxomab, marketed as Removab by Germany's Fresenius Biotech and Trion Pharma, has a specific binding affinity both for tumor cells and for T cells, which help mediate cancer cell killing. Removab is also recognized by immune cells such as macrophages, which engulf and destroy the cancer cells bound to the drug, thus giving the product multispecific function.

The European Medicines Agency approved Removab in April 2009 for the treatment of a cancer-associated condition in which fluid overwhelms the abdominal cavity in people with colon, pancreatic, breast or other types of cancer. The medication received orphan drug status from the FDA for the treatment of gastric and ovarian cancers, but remains unapproved in the US.

Given this background, makers of multispecific medicines might have a good shot at being able to circumvent the need to evaluate each of their drug components separately in clinical trials. But first, says Bill Martineau, an industry analyst with the Freedonia Group, a market research firm in Cleveland, "regulatory hurdles must be cleared before therapies based on these compounds will reach the market."

Roxanne Khamsi pharmaceutical companies already competing worldwide, notes Simon. But smaller biotech companies that "focus on US markets don't care about international collaboration as much," she says, and they therefore have less to gain.

Grace under fire: The first-to-invent patent legislation allows a oneyear grace period between the time an application is filed and the first time an inventor publicly discloses the product, either through publication or production. This grace period gives small, singleproduct biotech companies time to test the marketability of their drug or device before investing in a patent. Although lawmakers haven't yet outlined the details for disclosures, experts worry that "if disclosures are defined in a way that excludes public use or sale, it could threaten the economic viability of small companies," says Simon.

Meet your match: Many universities nowadays license their drug patents to pharmaceutical companies for manufacturing and marketing instead of doing it themselves, and they often won't go through the trouble of filing patents until they have a license in hand. The first-to-file system means they won't have the luxury of waiting; every minute universities spend seeking licensees before filing patents leaves time for an independent drug developer to apply first. However, if schools apply before finding an investor, "they're going to have a lot of unlicensed patents," says Rebecca Eisenberg of the University of Michigan Law School in Ann Arbor.

Running interference: Under current US guidelines, disputes about the first inventor of a product are decided at an 'interference proceeding' in front of a panel of judges. These costly and lengthy proceedings favored those with more time and money_namely, big pharma. "The little guy doesn't tend to win those interferences," says Arti Rai of the Duke University School of Law in Durham, North Carolina. But there should be few arguments about the date on the patent application under first-to-file, negating the need for interference hearings. "You can establish your application date. If it's before the other party, you're entitled to [the patent]," says David Resnick, a biotech patent attorney at Nixon Peabody in Boston. "With first-to-file there's certainty."

Hannah Waters 